\title{
Selection of reference genes for quantitative real-time PCR in bovine preimplantation embryos
} Karen Goossens ${ }^{1}$, Mario Van Poucke ${ }^{1}$, Ann Van Soom², Jo Vandesompele ${ }^{3}$, Alex Van Zeveren ${ }^{1}$ and Luc J Peelman*1

\author{
Address: ${ }^{1}$ Department of Animal Nutrition, Genetics, Breeding and Ethology, Faculty of Veterinary Medicine, Ghent University, Heidestraat 19, B- \\ 9820 Merelbeke, Belgium, 2Department of Reproduction, Obstetrics and Herd Health, Faculty of Veterinary Medicine, Ghent University, \\ Salisburylaan 133, B-9820 Merelbeke, Belgium and ${ }^{3}$ Center for Medical Genetics Ghent, Ghent University Hospital, Medical Research Building, \\ De Pintelaan 185, B-9000 Ghent, Belgium \\ Email: Karen Goossens - Karen.Goossens@UGent.be; Mario Van Poucke - Mario.VanPoucke@UGent.be; Ann Van \\ Soom - Ann.VanSoom@UGent.be; Jo Vandesompele - Joke.Vandesompele@UGent.be; Alex Van Zeveren - Alex.VanZeveren@UGent.be; \\ Luc J Peelman* - Luc.Peelman@UGent.be \\ ${ }^{*}$ Corresponding author
}

Published: 03 December 2005

BMC Developmental Biology 2005, 5:27 doi:10.1/86/147/-2/3X-5-27
Received: 09 June 2005

Accepted: 03 December 2005

This article is available from: http://www.biomedcentral.com/l47/-2/3X/5/27

(C) 2005 Goossens et al; licensee BioMed Central Ltd.

This is an Open Access article distributed under the terms of the Creative Commons Attribution License (http://creativecommons.org/licenses/by/2.0), which permits unrestricted use, distribution, and reproduction in any medium, provided the original work is properly cited.

\begin{abstract}
Background: Real-time quantitative PCR is a sensitive and very efficient technique to examine gene transcription patterns in preimplantation embryos, in order to gain information about embryo development and to optimize assisted reproductive technologies. Critical to the succesful application of real-time PCR is careful assay design, reaction optimization and validation to maximize sensitivity and accuracy. In most of the studies published GAPD, ACTB or I8S rRNA have been used as a single reference gene without prior verification of their expression stability. Normalization of the data using unstable controls can result in erroneous conclusions, especially when only one reference gene is used.

Results: In this study the transcription levels of 8 commonly used reference genes (ACTB, GAPD, Histone H2A, TBP, HPRTI, SDHA, YWHAZ and I8S rRNA) were determined at different preimplantation stages (2-cell, 8-cell, blastocyst and hatched blastocyst) in order to select the most stable genes to normalize quantitative data within different preimplantation embryo stages.

Conclusion: Using the geNorm application YWHAZ, GAPD and SDHA were found to be the most stable genes across the examined embryonic stages, while the commonly used ACTB was shown to be highly regulated. We recommend the use of the geometric mean of those 3 reference genes as an accurate normalization factor, which allows small expression differences to be reliably measured.
\end{abstract}

\section{Background}

Preimplantation bovine embryo development is characterized by distinct biological steps, including first cleavage division, activation of the embryonic genome, compaction and blastocyst formation with the derivation of two different cell lines, the inner cell mass and the trophectodermal cells. These processes are regulated by differential expression of developmentally important genes, mostly expressed in a stage- and time-dependent manner following the common maternal and/or embryonic expression 
pattern [1]. The acquisition of knowledge about the physiological timetable of gene expression during preimplantation development is crucial for a better understanding of mammalian embryo development and is useful for further refinement of assisted reproductive technology in mammals [2].

Until recently, most studies of oocyte and embryo physiology were based on microscopic observations, but it is commonly agreed that the evaluation of embryo morphology alone does not answer most of the questions [3]. New insights into preimplantation development were gained through the measurement of differential mRNA levels in oocytes and preimplantation embryos by Reverse Transcription (RT-) PCR methods [4-7] that replace less sensitive and more laborious methods like Northern blot analysis and RNase protection assay. However due to differential reaction efficiencies and kinetics in RT-PCR, the amount of final product after amplification may not accurately reflect the initial sample mRNA concentration [8].

Real-time RT-PCR assays in which data are accurately normalized, are significantly less variable than commonly used conventional RT-PCR procedures. Real-time quantification at the exponential phase is not affected by any reaction components becomming limited in the plateau phase. Although small differences in transcript levels can be measured by endpoint RT-PCR, a lot of optimizations and post-PCR manipulations are required. These optimizations have to be performed for every individual sample, because the RNA expression can vary a lot between individual samples. Therefore, real-time RT-PCR has been recognised as the method of choice for accurate and sensitive quantification of mRNA transcripts $[9,10]$. Many studies have now been published where RNA quantification has been assessed in early domestic animal embryos. This technique has the advantage of speed, high throughput and accuracy over a large dynamic range of quantification and is especially suitable when only a small number of cells are available [11]. Several authors [12-14] have demonstrated the reproducibility of the 2 step SYBR Green I real-time RT-PCR reaction by determination of the intraand interassay variation.

However, a lack of standards, variation in assay design, diversity of protocols, instruments and analysis methods make that real-time qRT-PCR results should be treated with caution and that agreed standards and operating procedures are required [15].

Several variables need to be controlled for gene-transcription analysis, such as the amount of starting material, enzymatic efficiencies, and differences between tissues or cells in overall transcriptional activity. Many methods are used to control some of these these variables, for example normalization against the total cell number, against the mass of the input material or against the RNA mass quantity. Exogenously added mRNA or spikes can be used for standardization when the spike is added before the RNA extraction [16].

Normalization against internal control genes is most frequently used because it can control all variables. Those internal control genes, also known as reference genes, are often referred to as housekeeping genes, assuming that those genes are expressed at a constant level in certain tissues, at all stages of development and are unaffected by the experimental treatment. To date most of the standardizations are done to reference genes such as $\beta$-actin (ACTB), glyceraldehyde 3-phosphate dehydrogenase (GAPD) or $18 S$ rRNA. However a number of studies have provided solid evidence that their transcription levels are not constant between different developmental stages and different experimental conditions [17-19]. Normalization of the data using these types of apparent controls can result in false conclusions being made regarding transcription levels. Therefore, validation of candidate reference genes is critical for accurate analysis of gene expression [20].

Most experiments include only a single reference gene. Vandesompele et al. [21] demonstrated that the conventional use of a single gene for normalization leads to relative large errors and they validated the geometric mean of multiple carefully selected reference genes as an accurate normalization factor.

In this study, we determined the mRNA expression levels of 8 commonly used reference genes at different preimplantation stages and calculated a normalization factor based on multiple control genes for more accurate and reliable normalization of gene-expression data in bovine preimplantation embryos.

\section{Results \\ Sample quality}

For each assay, embryos with good morphological characteristics [22] were selected from 3 different in vitro embryo production (IVP) experiments. The mean percentage of obtained embryos from all cultivated oocytes at the different developmental stages were $65 \pm 6 \%$ for the 2-cell stage, $44 \pm 5 \%$ for the 8 -cell stage, $25 \pm 4 \%$ for the blastocyst stage and $16 \pm 3 \%$ for the hatched blastocyst stage. Because IVP is time consuming and only a restricted amount of fertilized oocytes develop to the desired embryonic stages, the number of assays was restricted to 3 .

Total RNA was isolated from pools of 20 embryos per assay and for each examined developmental stage. Because of the very small cell numbers used for RNA 
Table I: Information on the primers used for real-time PCR

\begin{tabular}{|c|c|c|c|c|c|c|}
\hline Gene & Genbank Accession number & species & Sequence & Product size (bp) & $\mathrm{Ta}\left({ }^{\circ} \mathrm{C}\right)$ & $\%$ homology \\
\hline$A C T B[23]$ & AY 141970 & Cow & $\begin{array}{c}\text { 5'-CCTCACGGAACGTGGTTACA-3' 5'- } \\
\text { TCCTTGATGTCACGCACAATTT-3' }\end{array}$ & 87 & 58 & $100 \%$ \\
\hline GAPD & $\underline{X M \quad 618013}$ & Cow & $\begin{array}{l}\text { 5'-TTCAACGGCACAGTCAAGG-3' 5'- } \\
\text { ACATACTCAGCACCAGCATCAC-3' }\end{array}$ & 119 & 62 & $100 \%$ \\
\hline Histone $H 2 A^{[15]}$ & $\underline{\mathrm{U} 62674}$ & Mouse & $\begin{array}{l}\text { 5'-GTCGTGGCAAGCAAGGAG-3' 5'- } \\
\text { GATCTCGGCCGTTAGGTACTC-3' }\end{array}$ & 182 & 60 & $82 \%$ \\
\hline$T B P^{[33]}$ & NM 003194 & Human & $\begin{array}{c}\text { 5'-CCTAAAGACCATTGCACTTCG-3' } \\
\text { 5'-CTTCACTCTTGGCTCCTGTG-3' }\end{array}$ & 146 & 57 & $94 \%$ \\
\hline HPRTI & AFI76419 & Cow & $\begin{array}{l}\text { 5'-TGCTGAGGATTTGGAGAAGG-3' 5'- } \\
\text { CAACAGGTCGGCAAAGAACT-3' }\end{array}$ & 154 & 58 & $100 \%$ \\
\hline SDHA & NM 174178 & Cow & $\begin{array}{l}\text { 5'-GCAGAACCTGATGCTTTGTG-3' 5'- } \\
\text { CGTAGGAGAGCGTGTGCTT-3' }\end{array}$ & 185 & 60 & $100 \%$ \\
\hline YWHAZ & BM446307 & Cow & $\begin{array}{l}\text { 5'-GCATCCCACAGACTATTTCC-3' 5'- } \\
\text { GCAAAGACAATGACAGACCA-3' }\end{array}$ & 120 & 60 & $97 \%$ \\
\hline I $8 S$ rRNA & $\underline{A F I 76811}$ & Cow & $\begin{array}{c}\text { 5'-AGAAACGGCTACCACATCCA-3' 5'- } \\
\text { CACCAGACTTGCCCTCCA-3' }\end{array}$ & 169 & 62 & $100 \%$ \\
\hline
\end{tabular}

extraction, the RNA quantity could not be measured by the BioPhotometer (Eppendorf, Leuven) or the Nanodrop ND 1000 spectrophotometer.

A minus RT control demonstrated the presence of a considerable amount of contaminating genomic DNA. This illustrated the necessity of a DNase treatment, which removed all the contaminating genomic DNA from the RNA samples.

Although the RNA quality and quantity could not be determined, a real-time PCR with the reference gene GAPD gave cycle threshold $(\mathrm{Ct})$ values in the range of 23 to 27 and a single band on agarose gel. This first-strand cDNA was 2.5 times diluted with $10 \mathrm{mM}$ Tris $\mathrm{HCl} \mathrm{pH} 8$ and used for further real-time applications.

\section{Transcription profiling of the reference genes}

An initial screening of the transcription profiles of the selected reference genes by RT-PCR showed that all of those genes were expressed across the preimplantation embryo stages of interest. None of the eight selected genes was excluded from the study.

Gene-specific amplification was confirmed by a single peak in melt-curve analysis and a single band with the expected size in agarose gel electrophoresis. No primerdimer formation was detected and the identities of the PCR products were confirmed by sequencing (Table 1).

For all genes studied, standard curves derived from 10fold serial dilutions of pooled cDNA gave correlation coefficients greater than 0.97 and efficiencies greater than $90 \%$. The reaction efficiencies were used to transform the Ct-values into raw data for analysis with the geNorm software [21].
Three identical real-time qPCR assays were performed. In each assay the transcription levels of the selected reference genes were measured in duplicate, at 4 different stages of preimplantation development.

To compare the RNA transcription levels across the stages of embryonic development, the Ct values were compared. The Ct-value is defined as the number of cycles needed for the fluorescence signal to reach a specific threshold level of detection and is inversely correlated with the amount of template nucleic acid present in the reaction [23]. Most of the genes had $\mathrm{Ct}$ values in the range of 25 to 33 but $18 \mathrm{~S}$ $r R N A$ was more abundant (Ct levels <15).

\section{GeNorm analysis}

Analysis of the gene expression stability over the different embryonic stages was done using the geNorm software. The ranking of the 8 control genes according to their $M$ value was equivalent between the 3 assays. GAPD, YWHAZ, SDHA and 18S rRNA were the 4 most stable genes in each of the 3 assays, only the order of the genes was different. ACTB was the least stable gene in the 3 assays. The results are listed in Table 2.

To ensure comparability between the 3 assays, we compared the Ct values and efficiencies of the relative standard curves, derived from the same pooled cDNA stock, between the three independent assays and made a correction for the plate-to-plate variation according to the qBase algorithm (Hellemans et al., in preparation) [24]. This correction factor for inter-assay variation was necessary for the determination of the most stable reference gene over the 3 assays together. The results of the geNorm analysis of the combined assay are shown in Figure 1A. The ranking of the genes in this combined assay is in agreement with the ranking of the 3 individual assays. 
Table 2: Ranking of the reference genes in order of their expression stability per assay, decreasing from top to bottom. The reference genes chosen to calculate the normalization factor are printed in bold.

\begin{tabular}{cccc}
\hline Assay I & Assay 2 & Assay 3 & Combined* \\
\hline SDHA & SDHA & GAPD & GAPD \\
I8S rRNA & GAPD & YWHAZ & YWHAZ \\
GAPD & $I 8 S$ rRNA & I8S rRNA & I8S rRA \\
YWHAZ & YWHAZ & SDHA \\
HPRTI & Histone H2A & SDA & Histone H2A \\
Histone H2A & HPRTI & Histone H2A & TBP \\
TBP & TBP & TBP & TBPTI \\
ACTB & ACTB & HPRTIB & ACTB
\end{tabular}

*After correction for run-to-run variation

To determine how many reference genes should be used, normalization factors $\left(\mathrm{NF}_{\mathrm{n}}\right)$, based on the geometric mean of the expression levels of the $n$ best reference genes, were calculated by stepwise inclusion of an extra, less stable reference gene according to Vandesompele et al. [21]. Figure $1 \mathrm{~B}$ shows the pairwise variation $V_{n} / V_{n+1}$ between 2 sequential normalization factors $\mathrm{NF}_{\mathrm{n}}$ and $\mathrm{NF}_{\mathrm{n}+1}$. A large variation means that the added gene has a significant effect and should probably be included for calculation of the normalization factor. In this case, the inclusion of a $4^{\text {th }}$ gene has no significanf effect (low $\mathrm{V}_{3 / 4}$ value) on the NF. The 3 member set GAPD, SDHA and YWHAZ is an excellent choice for the calculation of the NF.

\section{Discussion}

Analysis of expression patterns of genes essential in early embryo development, provides a useful tool to assess the normality of the embryos and a tool to optimize assisted reproduction technologies [25]. New insights into early embryo development of mammals are commonly gained through the measurement of different mRNA levels by real-time qPCR. This technique has revolutionized the quantification of mRNA but requires careful assay design and reaction optimization to maximize sensitivity, accuracy and precision [26].

The problem of measuring transcript levels throughout preimplantation development is confounded by the fact that cell numbers and cell sizes are constantly changing during this developmental interval. Untill the maternalzygotic transition, the mRNA is mainly of maternal origin. Once the genome is activated, the cell number will influence the amount of mRNA available [3]. To allow ontogenic analysis, the embryos were compared as a single unit and the reference genes will correct for the differences between the embryos.

Using in vitro culture, another variable that must be taken into account is the proportion of normal embryos in the sample. Incompetent embryos may be mixed with compe- tent embryos during the analysis [3]. The gene expression in incompetent embryos may be different from those in competent embryos and could introduce a bias [27-29]. As such, there might be an influence of abnormal embryos on the choice of reference genes when using single embryo samples. Therefore we used groups of 20 pooled embryos with good morphological characteristics to minimize the influence of the quality of the individual embryo.

RNA quality and quantity are critical for succesful gene expression analysis. Due to the limited amount, RNA analysis was not possible, but an RNA extraction method optimized for small sample quantities, DNase treatment and appropriate control methods resulted in as reliable as possible results.

Critical to the successful application of real-time qPCR is the prevention of amplification of contaminating genomic DNA, resulting in an overestimation of the amount of RNA present. But even more importantly, yielding unreliable data especially for low abundant single exon genes or genes with retropseudogenes in the genome. Minus RT-controls before and after the DNAse treatment demonstrated the necessity and efficacy of the DNase treatment.

When intercalating dyes such as SYBR green I are used, attention should be paid to the formation of primer-dimers. Melting curve analysis and agarose gel electrophoresis confirmed that the fluorescent signal was specifically from the desired amplicons, not from artefacts.

Accurate normalization is required to correct real-time data for differences in cellular input, RNA quality and enzymatic efficiency between the samples. Under controlled conditions of reproducable extraction of good-quality RNA, the gene transcript number is ideally standardized to the number of cells [21]. During the bovine preimplantation period the cell numbers and cell size are constantly 
A

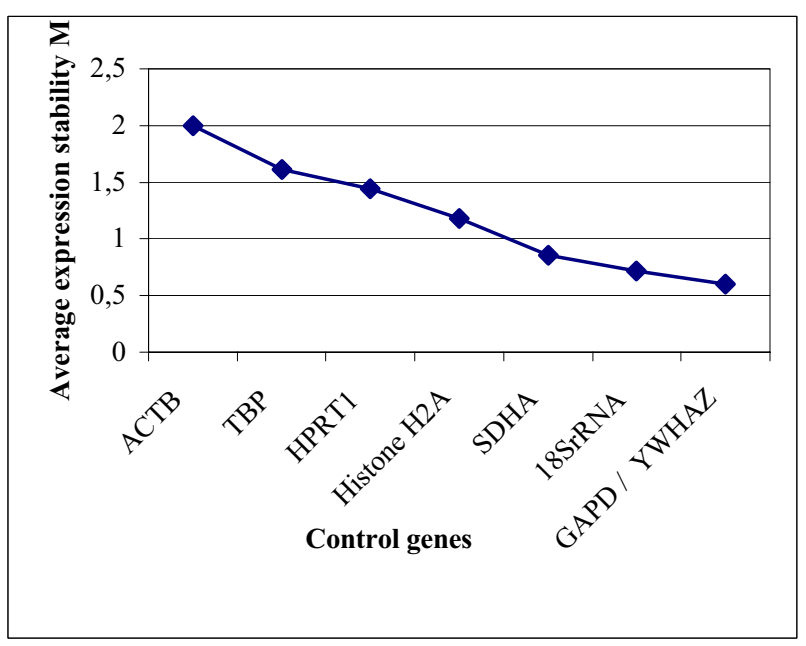

$\mathbf{B}$

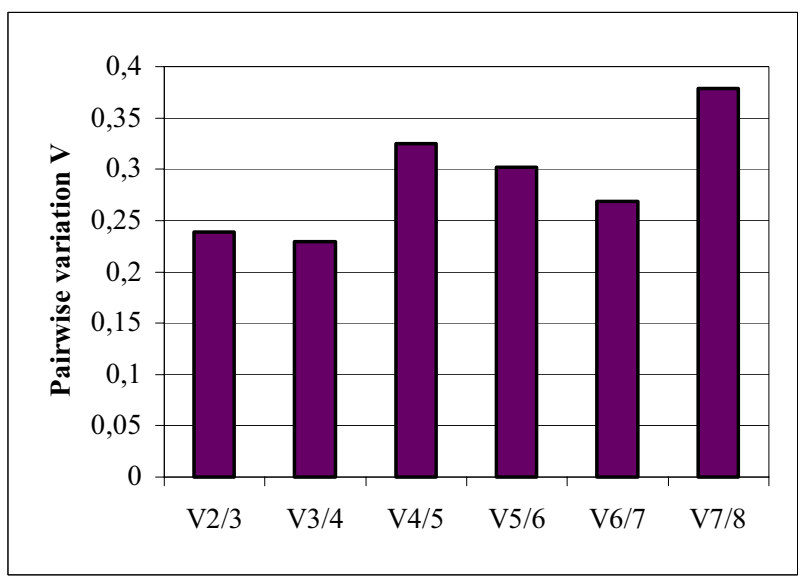

Figure I

(A-B): Gene expression stability of the candidate reference genes analyzed by the geNorm program. (A) Average expression stability values $(M)$ of the control genes over the 3 assays together, plotted from least stable (left) to most stable (right). (B) Pairwise variation analysis over the 3 assays together between the normalization factors $N_{n}$ and $\mathrm{NF}_{\mathrm{n}+1}$, to determine the optimal number of control genes for normalization. The higher $\mathrm{V}_{4 / 5}$ and $\mathrm{V}_{7 / 8}$ values are due to the inclusion of a relative unstable gene and are in accordance with the average expression stability $M$.

changing. Comparing mRNA levels within the same developmental stage is feasible but doing ontogenic analyses, which are essential to understand transitions in gene expression, is more problematic [3].
Another way of normalization is using the mass of the input material. However, in our case it was impossible to quantify those parameters because only minimal amounts of RNA were available and the total amount of RNA present throughout the preimplantation period is not constant. So normalization to total RNA requires a reliable RNA quantification method, and fails to take into account the variability of the RT-reaction. Probably the strongest argument against the use of total RNA mass for normalization is the fact that it predominantly consists of rRNA molecules and is not always representative of the mRNA fraction [21].

The addition of exogenously added mRNA can only be used when the exact amount of cells or starting material is known [16]. Spikes only correct for differences in enzymatic efficiencies but do not account for the quality and quantity of the input sample. Therefore, the use of spikes is not assumption free.

It is now generally accepted that transcription levels should be normalized to an invariable internal control gene. Those reference genes are often adapted from the literature and used against a variety of experimental conditions. An ideal reference gene should be expressed at a constant level among different experimental conditions and at all stages of development. An ontogenic study of several commonly used reference genes showed that their mRNA levels are not stable throughout preimplantation development [19]. If the used reference gene fluctuates between the samples, the subsequent normalization will cause erroneous results [30]. As the biological function of many genes is still unknown, it is difficult to predict how experimental conditions will affect the expression of the putative reference genes. Thus a safer approach is to use the geometric average expression of several genes that show small variance. Vandesompele et al. [21] postulated that gene pairs that have stable expression patterns relative to each other are proper control genes. YWHAZ, GAPD, SDHA and 18S rRNA were found to be the best endogenous control genes in preimplantation embryo samples as represented by their low $\mathrm{M}$ values, the marker of gene stability. ACTB was the worst scoring reference gene, in the set of 8 tested reference genes (Figure 1A). This is a remarkable result given the fact that in several publications on gene expression analysis in embryos, ACTB was the only reference gene used. However, the differential mRNA expression of ACTB is in accordance with previous reports that prove the upregulation of $A C T B$ during preimplantation embryo development and predict a role for ACTB during blastocyst formation [31-33]. In previous studies Histone $\mathrm{H} 2 \mathrm{~A}$ was determined as the most stable reference gene during preimplantation embryo development $[8,19]$, but those authors only considered Ct values and did not correct for the amount of input mate- 
Table 3: Functions of the selected reference genes

\begin{tabular}{lll}
\hline Symbol & Gene name & Function \\
\hline ACTB & B-actin & Cytoskeletal structural protein \\
GAPD & Glyceraldehyde-3-phosphate dehydrogenase & Glycolytic enzyme \\
Histone H2A & Histone 2 alpha & Nucleosome structure \\
TBP & TATA box binding protein & General RNA polymerase II transcription factor \\
HPRTI & Hypoxanthine phosphoribosyl-transferase I & Purine synthesis in salvage pathway \\
SDHA & Succinate dehydrogenase flavoprotein subunit A & Electron transporter in the TCA cycle and respiratory chain \\
YWHAZ & Tyrosine 3-monooxygenase/tryptophan 5-monooxygenase & Signal transduction by binding to phosphoserine-containing \\
& activation protein, zeta polypeptide & proteins \\
I8S rRNA & I8S ribosomal RNA & Ribosome unit
\end{tabular}

rial. To validate the presumed stable expression of a given control gene, prior knowledge of a reliable measure to normalize this gene in order to remove any nonspecific variation is required. To address this circular problem, Vandesompele et al. [21] developed a gene-stability measure to determine the expression stability of control genes on the basis of non-normalized expression levels. By using this approach, the changing RNA content during the developmental stages was taken into account [34]. Besides geNorm, other programs and strategies are described in literature to select the best reference genes. BestKeeper [35] is an Excel-application also based on pairwise correlation. Normfinder [13] is a model based approach and enables estimation not only of the overall variation of the candidate normalization genes, but also of the variation between sample subgroups of the sample set.

A normalization factor (NF) based on the geometric mean of the best performing reference genes was calculated. The number of genes used to calculate this NF is a trade-off between practical considerations and accuracy. In this case, the 3 most stable reference genes were used to calculate the normalization factor $\left(\mathrm{NF}_{3}\right)$. Figure $1 \mathrm{~B}$ demonstrates that the inclusion of a $4^{\text {th }}$ reference gene has no significant contribution to the newly calculated normalization factor $\mathrm{NF}_{4}$.

Ultimately, our choice for the normalizing set is the geometric mean of the transcription levels of GAPD, SDHA and YWHAZ. $18 S$ rRNA was excluded because rRNA genes have general disadvantages when used as reference genes. Their transcription is carried out by RNA polymerase I, therefore the regulation of rRNA synthesis is independent from mRNA synthesis, which is carried out by RNA polymerase II [36]. Besides, rRNA genes are highly abundant compared to the target mRNA transcripts, this imbalance makes it difficult to accurately subtract the baseline values in real-time qPCR analysis [21]. 18S rRNA was evaluated in this study because it is a commonly used reference gene.

\section{Conclusion}

In conclusion, a method for gDNA free RNA extraction from embryos was optimized and a reference gene assay for reliable normalization of real-time PCR data, obtained from bovine preimplantation embryo samples was designed. Transcription profiling of 8 different reference genes showed that the use of a single reference gene is not reliable and will result in erroneous conclusions. Instead GAPD, SDHA and YWHAZ should be used.

\section{Methods}

\section{In vitro production of bovine embryos}

Bovine embryos were produced by routine in vitro methods as described by Yuan and colleagues [37]. Briefly, bovine oocytes were obtained from ovaries collected at a local slaughterhouse. Immature cumulus-oocyte complexes were selected from follicular fluid, washed three times in HEPES-TALP and matured for 22 to $26 \mathrm{~h}$ in groups of 100 in $500 \mu \mathrm{l}$ maturation medium at $39^{\circ} \mathrm{C}$ in a humified $5 \% \mathrm{CO}_{2}$ incubator. After maturation the oocytes were inseminated with frozen-thawed sperm of a dairy bull $\left(1 \times 10^{6}\right.$ spermatozoa $\left./ \mathrm{ml}\right)$. The cumulus cells and spermatozoa were mechanically removed from the presumptive zygotes, which were placed in groups of 25 in 50 $\mu \mathrm{l}$ droplets of synthetic oviduct fluid supplemented with $5 \%$ fetal calf serum and cultured up to the desired stages. The embryos were collected at the indicative time period after fertilization: 2-cell (24-36 h), 8-cell (48-64 h), blastocyst (day 7) and hatched blastocyst (day 8). All embryos were washed three times in PBS, collected in pools of 20 and frozen at $-80^{\circ} \mathrm{C}$ until RNA extraction.

\section{RNA extraction and CDNA synthesis}

Total RNA was isolated from 20 pooled embryos using the PicoPure RNA Isolation Kit (Arcturus, Mountain View, 
CA) according to the manufacturer's instructions. This kit is engineered to recover high-quality total RNA from picoscale samples.

For genomic DNA removal an in-solution DNase digestion was carried out by treating the total RNA with 2 units of RQ1 DNase (Promega, Leiden) followed by a spin-column purification (Microcon YM-100, Millipore, Brussels). A minus RT control was performed with primers for GAPD to check the removal of all the contaminating genomic DNA.

First-strand cDNA was synthesized from the total amount of RNA using the iScript cDNA synthesis kit (Bio-Rad, Nazareth), following the manufacturer's instructions. The iScript Reverse Transcriptase is a modified MMLV-derived reverse transcriptase and the iScript Reaction Mix contains both oligo(dT) and random primers. After the RT reaction and RT control with primers for GAPD, the CDNA was 2.5 times diluted in $10 \mathrm{mM}$ Tris $\mathrm{HCl} \mathrm{pH}$ 8.0.

\section{Reference gene selection and primer design}

Eight reference genes were selected (ACTB, GAPD, Histone H2A, TBP, HPRT1, SDHA, YWHAZ and 18S rRNA) that belong to different functional classes to reduce the chance that the genes might be co-regulated (Table 3 ).

Primers for Histone H2A were taken from Robert and colleagues [19], primers for TBP were taken from Vigneault and colleagues [38] and primers for АCTB were taken from Fair and colleagues [27]. The other primers were designed by the Primer 3 software [39] and were based on RNA or DNA sequences found in Genbank. The reported bovine sequences were preferentially used and the specificity of the primers was tested using a BLAST analysis against the genomic NCBI database. PCR amplicons were characterized using Mfold [40] in order to predict the nature of any secondary structures which might influence the PCR efficiency. The PCR products were cloned (pCR 2.1 vector, Invitrogen, Merelbeke) and sequenced for verification (Thermo Sequenase Primer Cycle Sequencing Kit, Amersham Bioscience, Roosendaal) with a ALF Express sequencer (Amersham Bioscience, Roosendaal) [GenBank: DQ066891， DQ066892， DQ066893, DQ066894，DQ066895，DQ066896，DQ066897 and DQ066898]. Primer and amplicon information are listed in Table 1.

\section{Real-Time quantitative PCR}

Three replicates of 20 pooled embryos were used for each developmental stage (2-cell, 8-cell, blastocyst and hatched blastocyst) as described by Robert et al. [19].

All PCR reactions were performed in a $15 \mu \mathrm{l}$ reaction volume on the iCycler iQ Real-Time PCR Detection System
(Bio-Rad, Nazareth) using the iQ SYBR Green Supermix (Bio-Rad, Nazareth), $200 \mathrm{nM}$ of each specific primer and $2.5 \mu \mathrm{l}$ of diluted cDNA or one embryo equivalent per reaction.

The PCR program consisted of an initial denaturation step at $95^{\circ} \mathrm{C}$ for 3 minutes to activate the Taq DNA polymerase, followed by 45 cycles of denaturation at $95^{\circ} \mathrm{C}$ for 20 seconds and a combined primer annealing/extension at the specific annealing temperature for 40 seconds during which fluorescence was measured. A melt curve was produced to confirm a single gene-specific peak and to detect primer/dimer formation by heating the samples from 70 to $95^{\circ} \mathrm{C}$ in $0.5^{\circ} \mathrm{C}$ increments with a dwell time at each temperature of 10 seconds while continuously monitoring the fluorescence. PCR efficiencies were calculated using a relative standard curve derived from a pooled cDNA mixture (a ten-fold dilution series with four measuring points). This pooled cDNA was obtained from bovine heart, kidney, liver, muscle, lung and placenta tissue, using Total RNA Isolation Reagent (TRIR, ABgene, Epsom) for the RNA isolation and the iScript cDNA synthesis kit (Bio-Rad, Nazareth) for the RT-reaction.

Each reaction was run in duplicate, whereby a no-template control was included.

\section{Determination of reference gene expression stability}

To determine the stability of the selected reference genes, the geNorm Visual Basic application for Microsoft Excel was used as described by Vandesompele et al. [21].

This approach relies on the principle that the expression ratio of two perfect reference genes should be identical in all samples, regardless of the experimental condition or cell type. Increasing variation in this ratio corresponds to decreasing expression stability. The program calculates the gene stability measure $M$ by determining the average pair-wise variation between a particular reference gene and all other control genes. Genes with higher $M$ values have greater variation in RNA expression. By stepwise exclusion of the least stable gene and recalculation of the $M$ values, the most stable reference genes are identified. Finally, a normalisation factor (NF) was calculated based on the geometric mean of the expression levels of the bestperforming reference genes.

\section{Authors' contributions}

KG performed all the experimental procedures and was the primary author of the manuscript. MVP participated in the study design and provided real-time support. AVS contributed to the IVF experiments. JV provided expert input in data analysis. AVZ and LJP participated in the design of the project, helped to draft the manuscript and 
supervised the study. All authors read and approved the final manuscript.

\section{Acknowledgements}

The authors like to thank Machteld Baetens, Bieke Scharlaken, Johanna Mestagh and Griet Spaepen for their excellent technical assistance.

\section{References}

I. Niemann H, Wrenzycki C: Alterations of expression of developmentally important genes in preimplantation bovine embryos by in vitro culture conditions: implications for subsequent development. Theriogenology 2000, 53:21-34.

2. Steuerwald N, Cohen J, Herrera RJ, Brenner CA: Analysis of gene expression in single oocytes and embryos by real-time rapid cycle fluorescence monitored RT-PCR. Mol Hum Reprod 1999, II:1034-1039.

3. Sirard MA, Dufort I, Vallée M, Massicotte L, Gravel C, Reghenas H, Watson AJ, King WA, Robert C: Potential and limitations of bovine-specific arrays for the analysis of mRNA levels in early development: premilimary analysis using a bovine embryonic array. Reprod Fertil Dev 2005, 17:47-57.

4. Zhang X, Kidder GM, Zhang C, Khamsi F, Armstrong DT: Expression of plasminogen activator genes and enzymatic activities in rat preimplantation embryos. I Reprod Fertil 1994, 1 01:235-240.

5. Gutierrez-Adan A, Behboodi E, Murray JD, Anderson GB: Early transcription of the SRY gene by bovine preimplantation embryos. Mol Reprod Dev 1997, 48:246-250.

6. Wrenzycki C, Hermann D, Carnwath JW, Niemann H: Expression of RNA from developmentally important genes in preimplantation bovine embryos produced in TCM supplemented with BSA. J Reprod Fertil 1998, I | 2:387-398.

7. Wrenzycki C, Herrmann D, Niemann H: Timing of blastocyst expansion affects spatial messenger RNA expression patterns of genes in bovine blastocysts produced in vitro. Biol Reprod 2003, 68:2073-2080

8. Jeong YJ, Choi HW, Shin HS, Cui XS, Kim NH, Gerton GL, Jun JH: Optimization of real-time RT-PCR methods for the analysis of gene expression in mouse eggs and preimplantation embryos. Mol Reprod Dev 2005, 71:284-289.

9. Bustin SA: Absolute quantification of mRNA using real-time reverse transcription polymerase chain reaction assays. J Mol Endocrinol 2000, 25:169-193.

10. Bustin SA: Quantification of mRNA using real-time reverse transcription PCR (RT-PCR): trends and problems. J Mol Endocrinol 2002, 29:23-39.

I I. Fink L, Seeger W, Ermert L, Hanze J, Stahl U, Grimminger F, Kummer W, Bohle RM: Real-Time quantitative RT-PCR after laserassisted cell picking. Nat Med 1998, 4:1329-I333

12. Vandesompele J, De Paepe A, Speleman F: Elimination of primerdimer artifacts and genomic coamplification using a twostep SYBR Green I Real-Time RT-PCR. Anal Biochem 2002, 303:95-98.

13. Andersen CL, Jensen JL, Ørntoft TF: Normalization of real-time quantitative reverse transcription-PCR data: a model-based variance estimation approach to identify genes suited for normalization, applied to bladder and colon cancer data sets. Cancer Res 2004, 64:5245-5250.

14. Lai JP, Douglas SD, Wang YJ, Ho WZ: Real-time reverse transcription-PCR quantification of substance $P$ receptor (NKIR) mRNA. Clin Diagn Lab Immunol 2005, I 2:537-54I.

15. Bustin SA, Nolan T: Pitfalls of quantitative real-time reversetranscription Polymerase Chain Reaction. J Biomol Tech 2004 15:155-166.

16. Donnison M, Pfeffer PL: Isolation of genes associated with developmentally competent bovine oocytes and quantitation of their expression levels during development. Biol Reprod 2004, $71:|8| 3-|32|$

17. Thellin O, Zorzi W, Lakaye B, De Borman B, Coumans B, Hennen G, Gristar T, lgout A, Heinen E: Housekeeping genes as internal standards: use and limits. Biotechnol 1999, 75:291-295.

18. Suzuki T, Higgins PJ, Crawford DR: Control selection for RNA quantitation. Biotechniques 2000, 29:332-337.
19. Robert C, McGraw S, Massicotte L, Pravetoni M, Gandolfi F, Sirard MA: Quantification of housekeeping transcript levels during the development of bovine preimplantation embryos. Biol Reprod 2002, 67: | 465-| 472.

20. Zhang X, Ding L, Sandford AJ: Selection of reference genes for gene expression studies in human neutrophils by real-time PCR. BMC Mol Biol 2005, 6:4.

21. Vandesompele J, De Preter K, Pattyn F, Poppe B, Van Roy N, De Paepe A, Speleman F: Accurate normalization of Real-Time quantitative RT-PCR by geometric averaging of multiple internal control genes. Genome Biol 2002, 3:34 [http:// medgen.ugent.be/ jvdesomp/genorm/].

22. Van Soom A, Mateusen B, Leroy J, De Kruif A: Assessment of mammalian embryo quality: what can we learn from embryo morphology? Reprod Biomed Online 2003, 7:664-670.

23. Walker NJ: Tech Sight. A technique whose time has come. Science 2002, 296:557-559.

24. Hellemans : qBase Management and automated analysis of real-time quantitative PCR data. [http://medgen.ugent.be/ qbase/].

25. Wrenzycki C, Herrmann D, Lucas-Hahn A, Korsawe K, Lemme E, Niemann $\mathrm{H}$ : Messenger RNA expression patterns in bovine embryos derived from in vitro procedures and their implications for development. Reprod Fertil Dev 2005, 17:23-35.

26. Peters IR, Helps CR, Hall EJ, Day MJ: Real-time RT-PCR: considerations for efficient and sensitive assay design. J Immunol Methods 2004, 286:203-217.

27. Fair T, Murphy M, Rizos D, Moss C, Martin F, Boland MP, Lonergan P: Analysis of differential maternal mRNA expression in developmentally competent and incompetent bovine two-cell embryos. Mol Reprod Dev 2004, 67: | 36-I 44.

28. Donnison M, Pfeffer PL: Isolation of genes associated with developmentally competent bovine oocytes and quantitation of their levels during development. Biol Reprod 2004, 7I:I8I3-182I.

29. Gardner DK, Lane M: Ex vivo embryo development and effects on gene expression and imprinting. Reprod Fertil Dev 2005, I7:36I-370

30. Dheda K, Huggett JF, Bustin SA, Johnson MA, Rook G, Zumla A: Validation of housekeeping genes for normalizing RNA expression in real-time PCR. Biotechniques 2004, 37:1 I2-11 9.

31. Tanaka TS, Ko MS: A global view of gene expression in the preimplantation mouse embryo: morula versus blastocyst. Eur J Obstet Gynecol Reprod Biol 2004, I I 5:85-9I.

32. Bilodeau-Goeseels S, Schultz GA: Changes in the relative abundance of various housekeeping gene transcripts in in vitroproduced early bovine embryos. Mol Reprod Dev 1997, 47:413-420.

33. Giebelhaus DH, Weitlauf HM, Schultz GA: Actin mRNA content in normal and delayed implanting mouse embryos. Dev Biol 1985, 107:407-4I3.

34. Bilodeau-Goeseels S, Schultz GA: Changes in ribosomal nucleic acid content within in vitro-produced bovine embryos. Biol Reprod 1997, 56:1323-1329.

35. Pfaffl MW, Tichopad A, Prgomet C, Neuvians TP: Determination of stable housekeeping genes, differentially regulated target genes and sample integrity: BestKeeper - Excel-based tool using pair-wise correlations. Biotechnol Lett 2004, 26:509-5I5.

36. Radonic A, Thulke S, Bae HG, Müller MA, Siegert W, Nitsche A: Reference gene selection for quantitative real-time PCR analysis in virus infected cells: SARS corona virus, Yellow fever virus, Human Herpesvirus-6 and Cytomegalovirus infections. Virol J 2005, 2:7.

37. Yuan YQ, Van Soom A, Leroy JLMR, Dewulf J, Van Zeveren A, de Kruif A, Peelman LJ: Apoptosis in cumulus cells, but not in oocytes, may influence bovine embryonic developmental competence. Theriogenology 2005, 63:2147-2163.

38. Vigneault C, McGraw S, Massicotte L, Sirard MA: Transcription factor expression patterns in bovine in vitro-derived embryos prior to maternal-zygotic transition. Biol Reprod 2004, 70:1701-1709.

39. Rozen S, Skaletsky H: Primer3 on the WWW for general users and for biologist programmers. Methods Mol Biol 2000, 132:365-86 primer3 www.cgi] 
40. Zuker M: Mfold web server for nucleic acid folding and hybridization prediction. Nucleic Acids Res 2003, 31:3406-3415 [http:// www.bioinfo.rpi.edu/applications/mfold/old/dna/form l.cgi].

Publish with Bio Med Central and every scientist can read your work free of charge

"BioMed Central will be the most significant development for disseminating the results of biomedical research in our lifetime. " Sir Paul Nurse, Cancer Research UK

Your research papers will be:

- available free of charge to the entire biomedical community

- peer reviewed and published immediately upon acceptance

- cited in PubMed and archived on PubMed Central

- yours - you keep the copyright

Submit your manuscript here:

http://www.biomedcentral.com/info/publishing_adv.asp 